УДК 631.452:631.147(470.44/47)

https://doi.org/10.32634/0869-8155-2021-344-1-121-124

Оригинальное исследование/Original research

Семинченко Е.В.

Федеральное государственное бюджетное научное учреждение «Федеральный научный центр агроэкологии, комплексных мелиораций и защитного лесоразведения российской академии наук» (ФНЦ агроэкологии РАН) Университетский проспект, 97, 400062, Волгоград, Россия

Ключевые слова: органическое вещество урожайность, предшественники, приемы биологизации, плодородие почвы, органическое земледелие

Для цитирования: Семинченко Е.В. Урожайность севооборотов в зависимости от приемов биологизации. Аграрная наука. 2021; 344 (1): 121-124.

https://doi.org/10.32634/0869-8155-2021-344-1-121-124

Конфликт интересов отсутствует

\section{Seminchenko E.V.}

Federal State Budgetary Scientific Institution "Federal Scientific Center of Agroecology, Integrated Land Reclamation and Protective Afforestation of the Russian Academy of Sciences" (FSC Agroe-cology RAS) Universitetskiy prospect, 97, 400062, Volgograd, Russia e-mail: eseminchenko@mail.

Key words: organic matter, yield, predecessors, biologization techniques, soil fertility, organic farming

For citation: Seminchenko E.V. Crop rotation yield depending on from the receptions of biologization. Agrarian Science. 2021; 344 (1): 121-124. (In Russ.)

https://doi.org/10.32634/0869-8155-2021-344-1-121-124

There is no conflict of interests

\section{Урожайность севооборотов}

\section{в зависимости от приемов биологизации}

\section{PЕЗЮМЕ}

Среди приемов возделывания, повышающих урожайность культур, видная роль отводиться севообороту. В правильно построенном севообороте повышается эффективность всех агротехнических приемов, направленных на улучшение использования земли, удовлетворяются биологические потребности культур, достигается рациональное использование техники, снижение себестоимости произведенной продукции [1]. Почвы низко обеспечены азотом, средне - фосфором и повышенно - калием. Содержание гумуса $-1,2-2,0 \%, \mathrm{pH}=7-8$. Исследованиями установлено, что сидераты (донник, овес, фацелия) положительно влияют на баланс органического вещества. Отрицательный баланс органического вещества отмечается по чистому пару. Запас продуктивной влаги в слое почвы 0-0,3 см колебался от 4,1 до 29,5 мм у озимой пшеницы, 28,1-32,7 мм у нута и 28-35,3 мм у ярового ячменя в зависимости от погодных условий и приемов биологизации. В среднем за три года наибольшая урожайность была у озимой пшеницы по занятому пару (фацелия) и составила 1,0 т/га, которая зависела от погодных условий. Выявлена достоверная корреляционная связь по факторам урожайность-осадки; температура; элементы питания и т. д.

\title{
Crop rotation yield depending on from the receptions of biologization
}

\begin{abstract}
Among the methods of cultivation that increase the productivity of crops, a prominent role is assigned to crop rotation. In a properly constructed crop rotation, the efficiency of all agrotechnical methods aimed at improving the use of land increases, the biological needs of crops are satisfied, the rational use of technology is achieved, and the cost of production is reduced [1]. The soils are low in nitrogen, medium in phosphorus and high in potassium. The humus content is $1.2-2.0 \%, \mathrm{pH}=7-8$. Studies have shown that green manure (sweet clover, oats, phacelia) have a positive effect on the balance of organic matter. The negative balance of organic matter is noted for pure steam. The stock of productive moisture in the $0-0.3 \mathrm{~cm}$ soil layer varied from 4.1 to $29.5 \mathrm{~mm}$ for winter wheat, 28.1-32.7 mm for chickpea and 28-35.3 $\mathrm{mm}$ for spring barley, depending on the weather conditions. conditions and methods of biologization. On average, over three years, the highest yield was in winter wheat for a busy fallow (phacelia) and amounted to $1.0 \mathrm{t} / \mathrm{ha}$, which depended on weather conditions. A reliable correlation was revealed for the factors of yield-precipitation; temperature; batteries, etc.
\end{abstract}

Received: 10 november

Revised: 16 january

Accepted: 16 january 


\section{Введение}

На современном этапе функционирования сельского хозяйства немаловажное значение уделяется биологизации земледелия. Повышение продуктивности пашни и сохранения плодородия пахотных земель осуществляется за счет активизации биологических ресурсов. Возврат питательных веществ в почву происходит в процессе ежегодного поступления свежего органического вещества, активизации почвенной микрофлоры. Bсе агротехнические и биологические мероприятия осуществляются через биологизированные севообороты, основой которой является плодосмен. Особая роль в биологизации принадлежит многолетним травам и сидеральным парам.

\section{Объекты и методы исследований}

Исследования проводились на опытном поле $\mathrm{HB}$ НИИСХ, расположенном в светло-каштановой подзоне сухостепной зоны каштановых почв Нижнего Поволжья. Почва опытного участка светло-каштановая, тяжелосуглинистая с признаками заплывания и пятнами солонцов 15-20\%. Содержание гумуса 1,8-2,0\% pH водной вытяжки $(7,0-7,2)$, сумма поглощенных оснований 29 мг/экв. Опыт закладывали согласно методикам сухостепной зоны Нижнего Поволжья. Сумма осадков за 2017-2019 сельскохозяйственный год составила: 374,$9 ; 393,0$ и 387,3 мм против среднемноголетнего значения 339,2 мм. Высевали озимую пшеницу Камышанка 5 нормой высева 3 млн всхожих семян на 1 га, сорго на зерно Камышинское $64-300$ тыс., нут Приво 1 - 500 тыс., сафлор Александрит - 300 тыс., ячмень Медикум $139-3,8$ млн, яровая пшеница Камышинская $3-3,5$ млн, горчица Флагман Сарепты - 1,5 млн, овес Астор - 3,5 млн, донник желтый Колдыбанский - 6 млн, эспарцет Песчаный 1251 - 6 млн, люцерна Вега $87-$ 5 млн, фацелия Рязанская - 4 млн шт./га.

В опыте из полевых культур изучали озимую пшеницу, ячмень и нут при производстве зерна этих культур в биологизированных четырех, пяти и семипольных севооборотах по различным предшественникам и приемам биологизации.

Предшественниками озимой пшеницы были: 1) черный пар; 2) сидеральный пар (донник на сидерат); 3) сидеральный пар (овес на сидерат); 4) сидеральный пар (фацелия на сидерат). Яровой ячмень: 1) нут; 2) нут; 3) сафлор; 4) сорго. Нут: 1) озимая пшеница; 2) озимая пшеница; 3) горчица; 4) яровая пшеница.

Технологии возделывания озимой пшеницы, ярового ячменя и нута были общепринятыми для зоны проведения исследований. В четырехпольном севообороте солома и листостебельная масса полевых культур убирались с поля, в почву поступали их пожнивно-корневые остатки. В остальных севооборотах вся нетоварная часть возделываемых культур заделывалась в почву. В этих же севооборотах высевали соответственно донник, овес и фацелию на зеленое удобрение. Глубокая основная обработка почвы включала проведение чизелевания на 0,3-0,32 м с оборотом поверхностного пласта орудием О५О-5-40 и многофункциональными рабочими органами модульного типа «РАН-
4О». В первой декаде июня зеленую массу сидеральных культур дисковали орудием БДТ-3,8 на глубину 0,1-0,12 м. Зерновые культуры сеяли в оптимальные установленные для зоны исследований сроки.

\section{Результаты исследования и их обсуждения.}

Наблюдения в течение 2017-2019 годов показали, что внесение сидератов, соломы и запашка пожнивно-корневых остатков оказало благоприятное воздействие на изменение водного режима светло-каштановых почв.

Так, перед посевом озимой пшеницы (рис.) запасы продуктивной влаги по предшественнику пар сидеральный (фацелия на сидерат) в слое почвы 0-30см увеличились на 24 мм по отношению к контрольному севообороту (черный пар). Аналогичная тенденция сохранилась и по другим предшественникам.

Результаты полевых исследований выявили, что благодаря запашке зеленой массы сидеральных культур , в почву дополнительно поступают элементы питания. Поступление легкоусвояемых элементов питания позволяет поддерживать высокую продуктивность зерновых культур даже без минерального питания (табл. 1).

Анализ данных показывает, что высокий баланс органического вещества отмечается на озимой пшенице по предшественнику пар занятой (фацелия) в семипольном зернопаротравянопропашном сидеральном сеообороте - 4,05 т/га, немного ниже по предшественнику пар занятой (донник) в пятипольном зернопаровом сидеральном севообороте - 3,5 т/га. Средние значения баланса органического вещества отмечаются на яровом ячмене по предшественнику нут, сафлор, сорго в пяти и семипольных севооборотах. Низкие показатели получены на нуте по предшественнику озимая пшеница, горчица, яровая пшеница в пяти и семипольных севооборотах. Отрицательный баланс был получен в четырехпольном севообороте (контроль), так как вся товарная часть вывозилась с поля.

Оценивая влияние предшественников на продуктивность зерновой культуры, в среднем за три года (табл.1), при сложившихся погодных условиях наибольший сбор зерна получен на озимой пшенице по предшественнику пар занятой (фацелия) - 1,0 т/га, немного ниже результат получен тоже на озимой пшенице по предшественнику пар чистый, пар занятой (донник) и пар занятой (овес) в четырех, пяти и семипольных севооборотах 0,94 т/га. Изреживание посевов нута и ярового ячменя

Рис. Запас продуктивной влаги почвы в посевах озимой пшеницы в зависимости от предшественников и приемов биологизации (среднее за 2017-2019 годы)

Fig. Stock of productive soil moisture in winter wheat crops depending on predecessors and biologization techniques (average for 2017-2019)

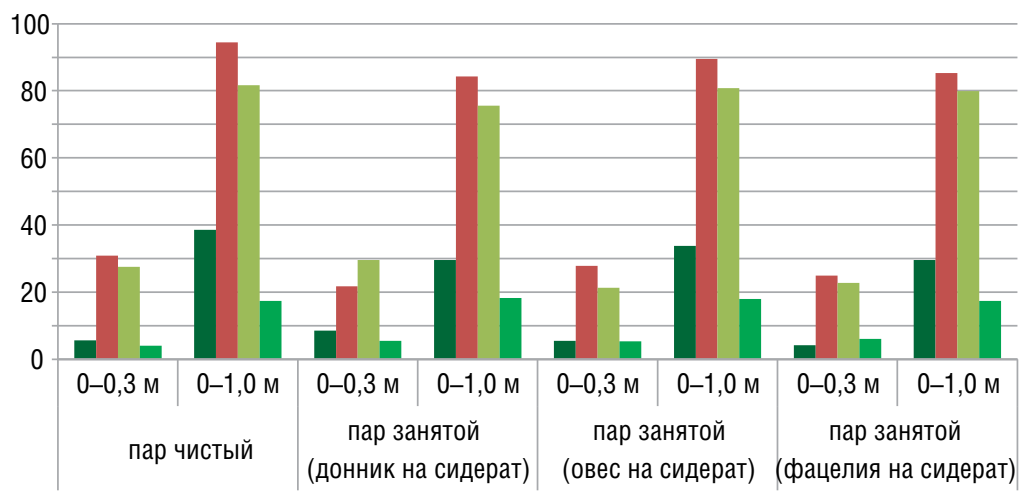

ппосев ууход в зиму весеннее отрастание пуборка 
Таблица 1. Баланс органического вещества и урожайность полевых культур в зависимости от предшественников в биологизированных севооборотах (среднее за 2017 2019 годы), т/га

Table 1. Balance of organic matter and yield of field crops, depending on the predecessors in biologized crop rotations (average for 2017-2019), t/ha

\begin{tabular}{|c|c|c|c|c|}
\hline $\begin{array}{l}\text { № вари- } \\
\text { анта }\end{array}$ & Культура & $\begin{array}{c}\text { Предшественник, } \\
\text { прием биологизации }\end{array}$ & $\begin{array}{c}\text { Баланс органиче- } \\
\text { ского вещества, т/га }\end{array}$ & Урожайность, т/га \\
\hline $1(\mathrm{k})$ & \multirow{4}{*}{$\begin{array}{c}\text { Пшеница } \\
\text { озимая }\end{array}$} & Пар чистый & $-1,1$ & 1,28 \\
\hline 2 & & $\begin{array}{c}\text { Пар занятый } \\
\text { (донник) }\end{array}$ & 3,5 & 1,22 \\
\hline 3 & & Пар занятый (овес) & 2,93 & 1,24 \\
\hline \multirow[t]{2}{*}{4} & & $\begin{array}{c}\text { Пар занятый } \\
\text { (фацелия) }\end{array}$ & 4,05 & 1,3 \\
\hline & & & & $\mathrm{HCP}_{05}=0,18$ \\
\hline $1(\mathrm{k})$ & \multirow{4}{*}{ Нут } & Пшеница озимая & $-0,26$ & 0,36 \\
\hline 2 & & $\begin{array}{c}\text { Пшеница озимая } \\
\text { (солома) }\end{array}$ & 0,59 & 0,25 \\
\hline 3 & & Горчица (солома) & 0,56 & 0,22 \\
\hline \multirow[t]{2}{*}{4} & & $\begin{array}{c}\text { Пшеница яровая } \\
\text { (солома) }\end{array}$ & 0,59 & 0,3 \\
\hline & & & & $\mathrm{HCP}_{05}=0,1$ \\
\hline $1(\mathrm{k})$ & \multirow{4}{*}{ Ячмень яровой } & Нут & $-0,86$ & 0,18 \\
\hline 2 & & Нут (солома) & 1,3 & 0,22 \\
\hline 3 & & Сафлор (солома) & 1,27 & 0,24 \\
\hline \multirow[t]{2}{*}{4} & & $\begin{array}{l}\text { Сорго зерновое } \\
\text { (солома) }\end{array}$ & 1,65 & 0,27 \\
\hline & & & & $\mathrm{HCP}_{05}=0,08$ \\
\hline
\end{tabular}

Таблица 2. Эмпирические модели севооборотов в зависимости от факторов

Table 2. Empirical models of crop rotations depending on factors

\begin{tabular}{|l|c|c|}
\hline \multicolumn{1}{|c|}{ Севооборот } & Уравнение множественной регрессии & R2 \\
\hline Четырехпольный севооборот & $y=0,40 X_{1}-0,40 X_{2}$ & 0,95 \\
\hline Пятипольный севооборот & $y=0,26 X_{1}-0,34 X_{2}$ & 0,88 \\
\hline Семипольный севооборот & $y=0,29 X_{1}-0,32 X_{2}$ & 0,91 \\
\hline Семипольный севооборот & $y=0,28 X_{1}-0,33 X_{2}$ & 0,92 \\
\hline
\end{tabular}

корреляции показывает тесноту связи по всему массиву и дает основание использовать для аппроксимации уравнение множественной регрессии (1) :

$$
\begin{aligned}
Y= & a+b_{1} X_{1}+b_{2} X_{2}+b_{3} X_{3}+ \\
& +b_{4} X_{4}+b_{5} X_{5}+b_{6} X_{6}
\end{aligned}
$$

По результатам статистических исследований были построены эмпирические модели урожайности зерновых культур по наиболее значимым факторам $\left(X_{1}\right.$ - осадки вегетационного периода, мм; $X_{2}$ - температура вегетационного периода, $C^{\circ} ; X_{3}$ - азот; $X_{4}-$ фосфор; $X_{5}-$ калий; $X_{6}-$ сорняки, шт). Анализ эмпирических моделей показал, что на продуктивность зерновых культур по различным предшественникам влияли температура воздуха и количество осадков в наиболее критические периоды развития.

Различные предшественники не оказали существенного влияния на зависимость метеоусловий на продуктивность зерновых культур, но лишь незначительно изменяли силу этой связи

В среднем за 3 года коэффициенты парной корреляции по всем предшественникам указывают между у и факторами имеют средние значения. Выявлена достоверная корреляционная связь урожайности - осадки $(R=+0,88 \ldots+0,95)$, температура $(R=+0,883 \ldots 0,94)$, азот $(R=+0,373 \ldots+0,754)$, фосфор $(R=+0,36 \ldots+0,834)$, калий $(R=+0,516 \ldots 0,981) ;$ сорняки $(R=+0,24 \ldots+0,431)$. На тесноту и величину связи по годам оказывают влияние условия вегетации растений.

Выводы. Таким образом, на основании проведенных исследова-

привело к увеличению засорения посевов многолетними и однолетними сорняками, что отрицательно сказалось на продуктивности зерновых культур.

За период вегетации зерновых культур по предшественникам, урожайность, температура воздуха, осадки, элементы питания и сорняки снижаются в виде линейной зависимости. Коэффициент множественной

\section{ЛИТЕРАТУРА}

1. Абуова А.Б. Урожайность масличных и зерновых культур в севооборотах Костанайской области. Вестник Алтайского государственного аграрного университета. 2012;5(91):5-8.

2. Перекрестов Н.В. Природные ландшафты Нижнего Поволжья. Известия Нижневолжского агроуниверситетскогокомплекса: наука и высшее профессиональное образование. 2008;(4):54-57.

3. Болдырь Д.А.. Селиванова В.Ю. Основная обработка почвы и эффективность использования атмосферных осадков яровыми культурами в Нижнем Поволжье. Научно-агрономический журнал. 2017;1(1):22-24.

4. Постников П.А. Продуктивность севооборотов при использовании приемов биологизации. Аграрный вестник Ура- ний можно сделать следующие выводы: для повышения урожайности зерновых культур и сохранения уровня органического вещества в почве необходимо провести замену чистых паров (возможно частично) на сидеральные, помимо используемых в хозяйстве органических удобрений вносить солому других зерновых культур и запахивать отаву многолетних трав.

ла. 2015;6(136):20-23.

5. Зеленев А.В., Уришев Р.Х., Семинченко Е.В. Эффективность средств биологизации в полевых севооборотах сухостепной зоны Нижнего Поволжья. Известия Нижневолжского агроуниверситетскогокомплекса: наука и высшее профессиональное образование. 2017;(1):63-69.

6. Кузьминых А.Н. Сидераты - важный резерв сохранения плодородия почвы. Земледелие. 2011;(4):41.

7. Арефьев А.Н., Кузина Е.Е., Кузин Е.Н. Приемы повышения плодородия черноземных и лугово-черноземных почв лесостепного Поволжья: монография. Пенза:Изд-во Пензенскогогос. агр. ун-та, 2017. 483 с.

8. Постников П.А., Попова В.В. Продуктивность сельскохозяйственных культур в полевых севооборотах. Аграрный вестник Верхневолжья. 2018;(2):5-11. 
9. Зеленев А.В., Семинченко Е.В. Солома - важный фактор биологизации при возделывании зернового сорго на светло-каштановых почвах Волгоградской области. Известия Нижневолжского агроуниверситетского комплекса: наука и высшее профессиональное образование. - 2018;(3): 62-69.

10. Усанова 3.И., Гуляев М.В. Влияние фона минерального питания и нормы высева на продуктивность посевов яровых зерновых культур в условиях Верхневолжья. Достижения науки и техники АПК. 2011;(11):24-27.

11. Al-Ghzawi, A.L.A., Al-Ajlouni, Z.I., Al Sane, K.O., Bsoul, E.Y., Musallam, I., Khalaf, Y.B., Al-Hajaj, N., Al-Tawaha, A.R., Aldwairi, Y., Al-Saqqar, H.. Yield stability and adaptation of

\section{REFERENCES}

1. Abuova A.B. Productivity of oilseeds and grain crops in crop rotations of Kostanay region. Bulletin of Altai State Agrarian University. 2012;5(91):5-8. (In Russ.)

2. Perekrestov N.V. Natural landscapes of the Lower Volg(In Russ.)a region. Proceedings of the Nizhne-Volga agro-university complex: science and higher professional education. 2008;(4):5457. (In Russ.)

3. Boldyr D.A. Selivanova V.Yu. The main soil cultivation and the efficiency of the use of atmospheric precipitation by spring crops in the Lower Volga region. Scientific and agronomic journal. 2017;1(1):22-24. (In Russ.)

4. Postnikov P.A. The productivity of crop rotations when using the methods of biology. Agrarian Bulletin of the Urals. 2015;6(136):20-23. (In Russ.)

5. Zelenev A.V., Urishev R.Kh., Seminchenko E.V. The effectiveness of biologization means in field crop rotations of the dry steppe zone of the Lower Volga region. Bulletin of the Nizhnevolzhsky agro-university complex: science and higher professional education. 2018;(3): 62-69. (In Russ.)

6. Kuzminykh A.N. Green manure is an important reserve for the preservation of soil fertility. Agriculture. 2011;(4):41. (In Russ.)

7. Arefiev A.N., Kuzina E.E., Kuzin E.N. Methods for increasing the fertility of chernozem and meadow-chernozem soils of the forest-steppe Volga region: monograph. - Penza: Publishing house of Penza. agr. un-ta, 2017. 483 p. (In Russ.)

\section{ОБ АВТОРЕ}

Семинченко Елена Валерьевна, н.с., соискатель, eseminchenko@mail.ru,https://orcid.org/0000-0003-3155-9563 four spring barley (Hordeum vulgare L.) cultivars under rainfed. Conditions Research on Crops.-2019;20(1):10-18.

12. Viljevac Vuletić, M.,Marček, T., Španić, V. Photosynthetic and antioxidative strategies of flag leaf maturation and its impact to grain yield of two field-grown wheat varieties Theoretical and Experimental. Plant Physiology. 2019;31(3):387-399 .

13. Cammarano, D., Hawes, C., Squire, G., Holland, J., Rivington, M., Murgia, T., Roggero, P.P., Fontana, F., Casa, R., Ronga, D. Rainfall and temperature impacts on barley (Hordeum vulgare L.) yield and malting quality in Scotland. Field Crops Research. 2019;241(1):107559.

8. Postnikov P.A., Popova V.V. The productivity of crops in field crop rotations. Agrarian Bulletin of the Upper Volga Region. 2018;(2):5-11. (In Russ.)

9. Zelenev A.V., Seminchenko E.V. Straw is an important factor of biologization in the cultivation of grain sorghum on light chestnut soils of the Volgograd region. Bulletin of the Nizhnevolzhsky agrouniversity complex: science and higher professional education. 2018;(3): 62-69. (In Russ.)

10. Usanova Z.I., Gulyaev M.V. The influence of the background of mineral nutrition and the seeding rate on the productivity of spring grain crops in the conditions of the Upper Volga region. 2011;(11):24-27. (In Russ.)

11. Al-Ghzawi, A.L.A., Al-Ajlouni, Z.I., Al Sane, K.O., Bsoul, E.Y., Musallam, I., Khalaf, Y.B., Al-Hajaj, N., Al-Tawaha, A.R., Aldwairi, Y., Al-Saqqar, H.. Yield stability and adaptation of four spring barley (Hordeum vulgare L.) cultivars under rainfed. Conditions Research on Crops.-2019;20(1):10-18.

12. Viljevac Vuletić, M.,Marček, T.,Španić, V. Photosynthetic and antioxidative strategies of flag leaf maturation and its impact to grain yield of two field-grown wheat varieties Theoretical and Experimental. Plant Physiology. 2019;31(3):387-399 .

13. Cammarano, D., Hawes, C., Squire, G., Holland, J., Rivington, M., Murgia, T., Roggero, P.P., Fontana, F., Casa, R., Ronga, D. Rainfall and temperature impacts on barley (Hordeum vulgare L.) yield and malting quality in Scotland. Field Crops Research. 2019;241(1):107559.

\section{ABOUT THE AUTHOR:}

E.V. Seminchenko, researcher, applicant, eseminchenko@mail.ru, https://orcid.org/0000-0003-3155-9563 